\title{
New insight on studying the effect of both chemical sensitivity and rock mechanical properties in shale formation to minimize wellbore instability problems
}

\author{
Mohammad H. Alqam ${ }^{1}$, Hazim H. Abass ${ }^{2}$ and Abdullah M. Shebatalhmad \\ ${ }^{1}$ Saudi Aramco, Dhahran, Saudi Aramco \\ ${ }^{2}$ Colorado School of Mines, Golden, Colorado, USA
}

\begin{abstract}
Historically, many of the wells drilled in in shale formations have experienced a significant rig downtime due to wellbore instabilities. Most of the instability problems originated from the encountered shale formations. The objectives of this study include (1) to measure the properties governing shale strength and drilling fluid/shale interaction, and (2) to establish a reliable and efficient rock mechanical testing procedures related to wellbore stability. Preserved shale core has been recovered from shale formation and special core handling procedure was implemented. Mineral oil was used for plugging and core preservation. Rock mechanical characterization was conducted on core samples using both XRD/SEM techniques to study the core mineralogy. In addition, shale permeability was determined by two methods: flow testing and pressure transition methods. The results indicated that shale has high percentage of quartz (30-40\%) which causes the shale to have high porosity and high permeability. The unconfined compressive strength of shale is very low which any drilling fluid that contains water phase further reduces. The Young's modulus is very low which makes near wellbore deformation high. Based on the shale swelling testing, the all-oil fluid show no volume change occurred to the shale. When the same shale was exposed to the $7 \% \mathrm{KCl}$, about $16 \%$ increase in core volume occurred in 48 hours. This means that all samples allowed the water to flow into the shale formation.
\end{abstract}

\section{Introduction}

Historically, drilling through shale formation usually causes over $90 \%$ of wellbore stability problems, which cost the industry more than $\$ 500$ million a year (Van Ooart et al, 1994). These problems can be a simple washout to complete collapse of the hole, which can lead to bit balling, sloughing, or creep. The problems of shale stability are related to the mechanical properties (strength and deformation under stress), the drilling fluids properties (chemical makeup and concentration), the insitu stress field, temperature, and time spent in open hole. Drilling extended-reach wells with long open hole intervals has been increasing. Oil based mud (OBM) have been the industry choice for difficult drilling. Their application has been typically justified based on borehole stability, fluid loss, filter cake quality, lubricity, and temperature stability. Water-based muds (WBM) are attractive replacements from a direct cost point-of-view. Past efforts to develop improved WBM for shale drilling have been hampered by a limited understanding of the drilling fluid/shale interaction phenomenon. This limited understanding has resulted in drilling fluids designed with

*Corresponding author: Mohammad.alqam@aramco.com non-optimum properties required to prevent the onset of borehole instability.

In general, borehole instabilities in shales can be controlled or managed via the following means: (1) specially designed mud systems; (2) adjusting the mud weight window; (3) reducing the exposure time of the drilled-out section to drilling mud; (4) adjusting hole trajectory. Realistic estimate of the mud weight depends on knowledge of the in-situ stress field and strength characteristics of the formation being drilled. Strength anisotropy of the shale will impact effective manipulation of the hole trajectory. Design of mud systems can only be optimized if knowledge about influence of the drilling fluid on the shale strength is known. Exposure time is generally based on field experience.

This study was initiated to tackle the following:

1. Obtain a preserved shale core.

2. Study the mineralogical characteristics to understand the swelling and dispersive properties of the shale formation.

3. Determine the elastic properties and strength characteristics under the effect of drilling fluid. Therefore, we need to test the shale in saturated condition after it is contacted with different drilling 
fluids. However, intact shale is impermeable. There is significant delicacy in saturating the shale sample completely and measuring the pore pressure change during the test. After the preserved cores are obtained, lab tests will be started to study the shale strength. At this stage, we will focus on influence of different mud types so that outcome of the tests will be immediately usable in the field. The drilling mud will be obtained from the lab-designed.

4. Determine shale permeability and pore-water activity.

5. Determine the effect of Chemico-Osmosis phenomenon. The clay-rich shale acts like a semiimpermeable membrane so that the exposed shale surface allows only water to move through, but not the ions. If the salinity of the mud is higher than that of the pore fluid in the shale, water will move out of the shale in order to reach equilibrium in the ionic concentration between them. It is generally recognized that the oil-based mud (OBM) makes a good semi-impermeable membrane. Therefore, the OBM is generally considered a good option in drilling through the shale provided the salinity of the water phase in the mud satisfies the above condition for the water to move out of the shale. On the other hand, water-based mud (WBM) only makes a leaky or imperfect semi impermeable membrane. Not only water, but also partially ions can move through the shale surface. The ion movement contributes to reaching the equilibrium between the mud and shale. Therefore, WBM reduces the effect of the osmotic flow in reducing the water content in the shale. WBM, using comparable mud salinity, is generally not preferred in drilling through the shale if environmental concern does not dictate its usage.

6. Determine shale swelling as a function of different drilling fluids. Clay content of the shale has large surface area and it adsorbs moisture. This will cause the shale to deteriorate and exhibit wellbore instabilities.

\subsection{Effect of Drilling Fluids on Shale Swelling}

Many different theories were presented to explain the swelling phenomenon of shales, such as capillary suction, osmosis pressure and hydraulic pore pressure overbalance. Low et al. (1958) studied the swelling of a soil and suggested osmosis as a mechanism for the swelling pressure in a soil. The theory was based on the principle that shale itself acts as a semi-permeable membrane. Chenevert (1970) used a balanced activity mud system to explain control on shale swelling. Chenevert et al. (1989) further added hydraulic pressure with the osmotic pressure to form a concept of total aqueous potential.

Barbour et al. (1989) presented a theoretical description of two mechanisms for osmotic volume change: changes in electrostatic forces between clay particles and flow out of/in due to the osmotic gradients. Fritz et al. (1983) supported the osmosis theory and further reported that clay membranes are not ideal. The ideality was a function of the membranes cation exchange capacity (CEC), porosity and concentration of pore fluid. A reflection coefficient was proposed to describe the ideality. Mody et al. (1993) further postulated that the membrane efficiency also depends on the confining pressure acting on the shale. Ballard et al. (1992) found that shales do not act as a semi-permeable membrane and ions are free to move across it. Bol et al. (1992) concluded after their experiments that osmosis was not observed. In both studies, however, the tested shales did not represent typical shales in highly stressed environment. Pashley et al. (1983) described the hydration forces and chemical mechanisms behind the ion movements between mica surfaces by taking into account the molecular interactions between clay particles and the ions in the pores and drilling fluid. Heidung et al. (1996) presented a hydrationswelling model by extending the poroelastic model and Darcy's law. Santarelli et al. (1995) pointed that the swelling is caused by gas present in the pore structure of the rocks, inducing capillary effects. It is unlikely for the swelling to occur downhole. Santos et al. (1996) contended that the moisture loss during sample handling and preparation causes the swelling observed in lab tests. Neither of these hypotheses, however, could not explain the success achieved by using balanced activity oil muds. The linear-swell meter (LSM) is used to determine shale hydration or dehydration by measuring time-dependant displacement of are constituted or intact shale core. There are many different theories to explain shale-swelling phenomenon based on capillary suction, osmotic pressure and hydraulic pressure. Shale samples were ground and passed through 200-mesh screen, and reconsolidated at $6.894 \times 10^{7}$ Pascal psi with $5 \%$ moisture to form a cylindrical plug $0.02 \mathrm{~mm}$ high and $25 \mathrm{~mm}$ in diameter. The plug was then placed in a desiccator at $29.5 \%$ relative humidity for 24 hours before using it for a swelling test. A mechanical confining force of 5.40 Newton was applied to the plug during the linear swelling test.

\section{Shale Mineralogy}

X-Ray Diffraction (XRD) was conducted on samples obtained from shale formation. The average values for the minerals are as follows: Quartz (55.6 wt \%), lllite $(0.1 \mathrm{wt}$ $\%)$, Kaolinite (32.5\%), Pyrite (3.1 wt \%), Microcline (1.45 wt \%), Albite (0.7 wt \%), Ankerite/ Dolomite (2.3 wt \%), and Siderite $(9.6 \mathrm{wt} \%)$. The crystalline structure of the minerals of Shale samples to be quartz, siderite, calcite, dolomite, ankarite, pyrite, albite, microcline and anhydrite. The clay patterns also show that the clay size fraction of samples consists mainly of kaolinite with lesser siderite, chlorite, and illite/smectite. Many of the results are approximate because of the heterogeneous nature of some of the samples, which consist of multiple rock types (i.e. sandstone, shale, calcareous shale and sandstone and coal).

Mechanical stresses around a wellbore placed at any arbitrary orientation in a 3 dimensional stress field are coupled with changes in temperature and pore pressure due to water and solute fluxes. The radial and azimuthal variation in the stress distribution and the failure index are 
computed to check for wellbore failure. This model accounts for the hindered diffusion of solutes as well as the osmotically driven flow of water into the shale. The model for the first time allows a user to study the role of solute properties on wellbore stability. Results from the model show that a maximum or minimum in pore pressure can be obtained within shale. This leads to wellbore failure not always at the wellbore wall as is most commonly assumed but to failure at some distance inside the shale. Since the fluxes of water and solute, and temperature, are time dependent, a clearly time dependent wellbore failure is observed. The time to wellbore failure is shown to be related to the rate of solute and water invasion.

Comparisons with experiments conducted with a variety of solutes on different shales show excellent agreement with model results. It is shown in this study that the solutes present in the mud play an important role in determining not only the water activity but also in controlling the alteration of pore pressures in shales. To account for this phenomenon a model is presented to compute the flux of both water and solutes into or out of shales. The relative magnitudes of these fluxes control the changes in pore pressure in the shale when it is exposed to the mud. The effect of the molecular size of the solute, the permeability of the shale and its membrane efficiency are some of the key parameters that are shown to determine the magnitude of the osmotic contribution to pore pressure. A range of behaviour is observed if the solute is changed while the water activity is maintained constant. This clearly indicates the importance of the solute flux in controlling the pore pressure in shales. Critical mud weights are obtained by inspecting the stability of the wellbore wall and the entire near wellbore region. Pore pressures at different time and position are investigated and presented to explain the model results. It is shown in this study that the critical mud weights are strongly time dependent. The effects of permeability, membrane efficiency of shale, solute diffusion coefficient, mud activity and temperature changes are presented in this work. The collapse and fracture effects of cooling and heating the formations are also presented. A powerful simulation tool has been developed which can be used to perform thorough investigations of the wellbore stability problem. A user-friendly interface has been developed to ease usage.

\section{Flow method}

Flow testing was considered to determine an average value of shale permeability for wellbore instability modelling. A shale sample was subjected to flow condition and the following data was obtained:

Intensifier Displacement: $1 \mathrm{~mm}$

Intensifier ID: $15.875 \mathrm{~cm}$

Volume Collected: $\Pi(1.5875 / 2) 2$ х $0.1=0.198 \mathrm{~cm}^{3}$

Time: 90420 second

Q: $0.0000021898 \mathrm{~cm}^{3} / \mathrm{min}$

L: $6.985 \mathrm{~cm}$

D: $3.825 \mathrm{~cm}$

Asample : $\Pi(3.825 / 2) 2=11.49 \mathrm{~cm}^{2}$

$$
\begin{array}{cc}
\Delta \mathbf{P}: & 5394.59 \text { Pascal } \\
\boldsymbol{\mu}: \quad 0.001 \text { Pasc } \\
Q=\frac{K A \Delta P}{\mu L}
\end{array}
$$

\subsection{Pressure transmition method}

A method described by Van Oort (1994) was used to estimate Shale permeability. The procedure entails subjecting a sample with length (L) and cross sectional area (A) that has an initial pore pressure (Po), to a constant upstream pressure (Pup) while the downstream pressure $(\mathrm{Pd})$ is measured for some time. The permeability is measured as follows:

$$
K=\frac{\mu c V L}{\mathrm{~A}} \quad \frac{\Delta \ln \frac{P_{u}-P_{0}}{P_{u}-P_{d}(t)}}{\Delta \mathrm{t}}
$$

where $\mathrm{V}$ is the downstream volume that should be full of same testing fluid and at a same pressure as the initial pore pressure, Po. The function $\ln =\frac{P_{u}-P_{0}}{P_{u}-P_{d}(t)} \quad$ is plotted against time to determine the linear portion of the graph as shown in the following Figure 1.

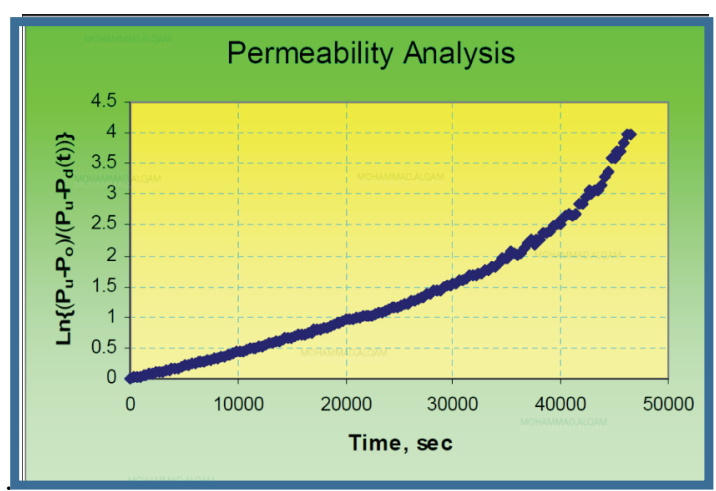

Figure 1. Linearization of the pressure response as a function of time.

\subsection{Effect of Drilling Fluids on Shale Strength}

Many rock mechanics tests were performed to evaluate the effect of drilling fluids; water based, invert emulsion (oil based), and all oil drilling fluids. All tests were performed at zero psi confining pressure. The all-oil saturated sample exhibits the highest strength. The Unconfined Compressive Strength (UCS) was 1232, 2191 , and 3107 psi for the $7 \% \mathrm{KCl}$, invert emulsion, and all-oil samples respectively. It is therefore recommended to use all-oil or synthetic oil based drilling fluid in problematic shale. It is important to point out that the oilbased drilling fluid (invert emulsion) include a water phase, which obviously is affecting shale strength.

\section{Mechanical properties}

The following sections summarize the experimental procedures for determining the mechanical properties: 


\subsection{Sample Preparation:}

Sample preparation includes the following steps:

- Select core plugs from a given formation.

- The end faces are surface grounded to become parallel and flat to within 0.001 inches.

- The sample is jacketed and two end caps equipped with velocity transducers are positioned on the ends of the sample with a couplant medium is set between the sample and a transducer.

\subsection{Sample Loading}

The following steps were made to load the sample:

- The jacket is clamped to the transducers from both ends to allow for hydraulically applying confining pressure around the sample as shown in Figure 1.

- Radial and axial LVTDs are positioned around and along the sample to measure radial and axial displacements respectively.

- Confining pressure is applied hydrostatically around the sample. The confining pressures are selected to simulate the stress condition in the vicinity of the wellbore.

\subsection{Sample Preparation}

Multi-stage and/or single stage loading are performed on selective samples, which involve loading the rock sample at a given confining pressure to failure (single stage), or near failure (multistage) then a new sample is tested or a new loading cycle is applied on same sample using different confining pressure. A Mohr-Coulomb failure envelope is then constructed from three to four tested samples or three to four loading cycles.

For multistage loading, a sample is hydrostatically loaded to a given confining pressure and the differential axial stress is increased slowly until a non-linear radial strain is observed upon which the sample is unloaded and a new confining pressure is applied to go through the next loading stage. Multi-stage loading is applied when it is determined that the sample is a good candidate for such testing methodology. It must be emphasized that the sample must not be loaded beyond the initiation of a plastic mode.

\subsection{Data Collection}

The triaxial loading system is presented in Figure 2. During the triaxial test, the following data was collected:

- Vertical stress, which is applied axially at an axial displacement rate of 3-6 mm/hr (4-8\% strain). The loading rate is applied such that failure or near failure is resulted within 5-15 minutes.

- Axial strain is measured from the two LVDTs positioned on two locations along the axial axis of the sample. The axial strain is calculated from averaging the readings of the two LVDTs.

- Radial strain from the radial LVDT.

- Confining pressure as provided by confining fluid.

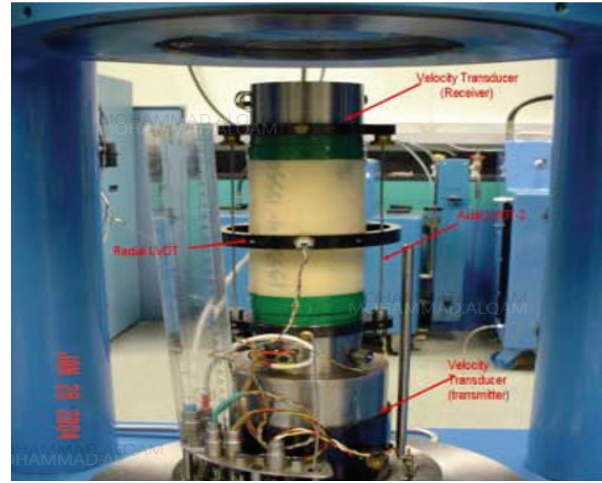

Figure 2: Rock mechanical loading frame

The testing of the shale for the mechanical properties yielded the following results that are summarized in Table 1:

- The unconfined compressive strength of shale is very low which is further reduced by any drilling fluid that contains water phase.

- The Young's modulus is very low which makes near wellbore deformation high.

- The tensile strength is very low indicating a drilling fluid loss to be excessive.

- All factors related to maintaining the already low compressive strength should be applied such as using all-oil/synthetic oil drilling fluid, reducing exposure time, increasing capillary pressure, and encouraging osmosis flow from the shale to the wellbore.

Table 1: Rock mechanical properties

\begin{tabular}{|c|c|c|}
\hline Young's modulus, psi & $1.2 \times 10^{6}$ & $1.7 \times 10^{6}$ \\
\hline Poisson's ratio & 0.131 & 0.131 \\
\hline UCS, psi & 2100 & 3125.1 \\
\hline Internal Friction Angle & $33^{\circ}$ & $33^{\circ}$ \\
\hline Cohesion, psi & 580 & 863.1 \\
\hline Tensile Strength, psi & 200 & 297.6 \\
\hline
\end{tabular}

\subsection{Conclusion}

Conclusions from this study indicate that shale has high percentage of quartz (30-40\%) causing high porosity and permeability. The shale formation shows a low percentage of Feldspars such as Albite and Microcline. Since Feldspar hardness is high, shale with low Feldspar content will disperse easily. Kaolinite was found to be the main clay components of shale and its percentage vary from 40$90 \%$. Kaolinite is dispersive and non-swelling clay.

\section{References}

1. Mody, F. K. and Hale, A. H.: "A Borehole Stability Model to Couple the Mechanics and Chemistry of Drilling Fluid/Shale Interaction," paper IADC/SPE 25728 presented at the IADC/SPE Drilling Conference, Amsterdam, February 23-25, (1993).

2. Van Oort, E., Hale, A. H., Mody, F. K., and Roy, S.: "Critical Parameters in Modeling the Chemical 
Aspects of Borehole Stability in Shales and in Designing Improved Water-Based Shale Drilling Fluids," paper SPE 28309 presented at the $69^{\text {th }}$ Annual Technical Conference and Exhibition of SPE, New Orleans, La., September 25-28, (1994).

3. Ballard, T. J., Beare, S. P., and Lawless T.A., "Fundamentals of Shale Stabilization: Water Transport Through Shales", SPE 24974, Presented at the European Petroleum Conference held in France, 16-18 November 1992.

4. Barbour, S. I., D, G. Fredlund. 1989. Mechanics of Osmotic flow and Volume change in clay soils. Canadian Geotechnical Journal 26: 551- 562.

5. Fritz, S.J., and I. W. Marine. 1983. Experimental Support for a Predictive Osmotic Model of Clay Membranes. Geochimica et Cosmochimica Acta 47: $1515-1522$.

6. Bol, G. M., Wong, S. W., Davidson, C. J., and Woodland, D. C.: "Borehole Stability in Shales," paper SPE 24975 presented at the SPE European Petroleum Conference, Cannes, France, November $16-18$ (1992).

7. Pashley, R. M., and J. N. Israelachvili, DLVO and Hydration forces between mica surfaces in $\mathrm{Mg}^{2+}$, $\mathrm{Ca}^{2+}, \mathrm{Sr}^{2+}$ and $\mathrm{Ba}^{2+}$ chloride solutions, J. Colloid Interface Sci. 97: 446 - 455 (1984).

8. Heidung, W.K. and Wong, S. W. 1996. Hydration Swelling of Water-Absorbing Rock: a Constitutive Model. International Journal of Numerical and analytical Methods in Geomechanics.

9. Santos, L.M.A.; Craveiro, S.C. \& Calado, A.J. (1996): Silica-scaled Chrysophytes from three $\alpha$ mesosaprobic water bodies of central Portugal. Beih. Nova Hedwigia 114: 171-191

10. Chenevert, M. E.: "Adsorptive Pore Pressure of Argillaceous Rocks, in Rock Mechanics Theory and Practice (W. H. Somerton, Ed.), Eleventh Symp. Rock Mech., Am. inst. Min., Metall., Pet. Eng., pp 599-627, (1970).

11. Low, P. F. and Deming, J. M.: "Movement and Equilibrium of Water in Heterogeneous Systems with Special reference to Soils," Soil Sci., v.71, pp 409418, (1953).

12. Chenevert, M.E., 1989. Glycerol mud additive provides shale stability. Oil Gas J., 60- 64 (July 17). 